13. Borgia V., Carlin M. G., Crezzini J. Poison, Plants and Palaeolithic Hunters. An Analytical Method to Investigate the Presence of Plant Poison on Archaeological Artefacts // Quaternary International. 2017. Vol. 427. Part. B. P. 94-103.

14. Borgia V. Plants, Poisons and Paleolithic Hunters // The Italian Academy for Advanced Studies in America : [сайт]. URL: https://italianacademy.columbia.edu/fellow/valentina-borgia (дата обращения: 16.02.2018).

УДК 130.2

Науч. спец.: 09.00.13

DOI: 10.36809/2309-9380-2020-26-18-22

\section{ФУНКЦИИ ИСКУССТВА В ЭПИСТЕМЕ АНТИЧНОЙ ФИЛОСОФИИ: ПРОБЛЕМА ПОТРЕБЛЕНИЯ КУЛЬТУРЫ}

В статье рассматривается проблема потребления искусства как феномена культуры, обладающего онтологическим (функция отображения действительности) и когнитивным (функция моделирования смыслов) статусом в философском дискурсе античной классики. Утверждается, что модус обладания, принципиально противоречащий модусу бытия в сознании современного человека в индустриальном обществе, исторически связан как с гедонистической традицией Античности, так и с утилитаризмом философских воззрений на искусство как общественно полезное умение.

Ключевые слова: философский дискурс, эпистемология, смыслы культуры, функции искусства, производство и потребление.
15. Сериков Ю. Б. К вопросу об оружии поражения луговского мамонта // Вестн. археологии, антропологии и этнографиии. 2012. № 1 (16). С. 4-11.

16. Жермонпре М., Саблин М. В., Хлопачев Г. А., Григорьева Г. В. Палеолитическая стоянка Юдиново: свидетельства в пользу гипотезы охоты на мамонтов // Хронология, периодизация и кросс-культурные связи в каменном веке. СПб. : Наука, 2008. Вып. 1. С. 91-112.

(C) Кассал Б. Ю., 2020

\title{
FUNCTIONS OF ART IN THE EPISTEME OF ANCIENT PHILOSOPHY: THE PROBLEM OF CONSUMPTION OF CULTURE
}

The article considers the problem of consumption of art as a phenomenon of culture, possessing ontological (function of reflecting reality) and cognitive (function of modeling meanings) status in the philosophical discourse of ancient classics. It is argued that the mode of possession, fundamentally contrary to the mode of being in the consciousness of modern man in the industrial society, is historically associated with both the hedonistic tradition of Antiquity and the utilitarianism of philosophical views on art as a socially useful skill.

Keywords: philosophical discourse, epistemology, cultural meanings, functions of art, production and consumption.

Высшей целью жизни и античная философия, идеалистическая по преимуществу, и филососрия современная, сформировавшаяся преимущественно в дискурсе неклассической рациональности, полагают счастье, определяемое формулой «удовлетворение всех желаний или субъективных потребностей», что является, по определению Э. Фромма, «радикальным гедонизмом»; эпикурейская «чистая радость» представляет его скромный инвариант. Древние различали чисто субъективно ощущаемые потребности, отчасти противоречащие человеческому развитию, имея в виду часто возникающие этические проблемы межличностных отношений и взаимоотношений индивида с социумом, и объективно существующие потребности, согласующиеся с нуждами человеческой природы. Применительно к современной ситуации надо отметить наличие имманентных экономических противоречий индустриализма; кроме того, существуют другие причины возникновения «противоречивых комбинаций приоритетов» [1, с. 12]. Иначе говоря, модус обладания принципиально противоречит модусу бытия [1, с. 63]. Сказанное имеет отношение к проблеме потребления культуры.
Онтологически фррагментированный тип сознания современного человека обусловлен нарастающей «всеобщностью смыслов культуры» [2, с. 258].

Современная философия разграничивает, в связи с проблемой метаязыка как коммуникативного канала, соединяющего две культуры - естественно-научную и гуманитарную, понятие культуры как таковой, культуры вообще, как модели «глобального междисциплинарного трансфера», и культуры как метонимии искусства, феномена, порождаемого культурой и репрезентирующего результаты творческого процесса, как модели творчества [3, с. 323]. Основанием всякого феномена человеческой культуры является коммуникативная потребность; культура в своих конкретных проявлениях, своим социальным бытованием включена в определенный когнитивный процесс. Коммуникативный аспект самого ее существования как культуры повседневности определяет ключевым моментом как культуротворчества, так и простого потребления культуры понимание смысла общения посредством определенных механизмов, управляющих процессом понимания: идею культурного дискурса может выражать как художественный текст, так и музыкальное 
сочинение, живописная картина, скульптура, архитектурное сооружение и т. п.

Античное понимание культуры не столь многозначно, напротив, узкоспециально. Римский по происхождению термин поначалу обозначал попросту возделанную почву, в том числе и в метафорическом значении, и почти не сфокусирован на культурном творчестве как одной из его функций, базовых характеристик. Культура - скорее цивилизация, нежели искусство - эстетическая устремленность человеческого бытия, сосредоточенная в прекрасных созданиях искусства. Если в социуме человеческая мысль жестко детерминирована социально значимой логикой рассуждения, то в феноменах культуры «моя» мысль порождается (всякий раз заново) изнутри и получает индивидуальное обоснование «всеобщих начал мышления» [2, с. 309]. Искусство является творчески полагаемым впервые общением автора с идеальным читателем, зрителем или слушателем, заданным смысловыми кодами художественного произведения. Таков зритель античной трагедии, необходимо отождествляющий себя с эпическим по форме самовыражения мифологическим сознанием трагедийного хора. Аристотель в «Поэтике» полагает задачей драматурга «говорить не о том, что было, а о том, что могло быть в силу вероятности или необходимости» [4, с. 655]. Трагедия - «подражание не людям, но действию, жизни, счастью и несчастью» [4, с. 652]; в художественной структуре ее органично соединяются склад событий (сказание), характеры, мысль, речь и зрелище.

Это означает, что возможности и функции искусства обусловлены как художественным творчеством самой природы (так Ф. Шлегель истолковывал поэтику мифа), метафорической глубиной отображения повседневной действительности, так и логикой долженствования, общественной (объективной) значимостью творений художника (субъективных образов действительности). Вспомним известные строки А. С. Пушкина: «Нет, если ты небес избранник, / Свой дар, божественный посланник, / Во благо нам употребляй...» [5, с. 88].

Искусством Платон считал «решительно всякую деятельность человека», а также, как разъяснял А. Ф. Лосев, «всякое его субъективное намерение» [6, с. 16]. Интеллектуальное понимание искусства сформулировано в диалоге «Кратил»; сам термин объясняется как «обладание умом». Однако в диалоге «Евтидем» всевозможные искусства (врачебное, корабельное, ораторское) оцениваются по принципу: то ли это искусство, благодаря которому человек может стать счастливым [7, с. 135]. Какова же гносеологическая основа таких утилитарных воззрений на искусство? И можно ли назвать такую точку зрения утилитаризмом, если коммуникаторы платоновского диалога задаются вопросом: почему так бывает, что одни живописцы - хуже, а другие - лучше? «И одни из них создают лучшие живописные произведения, а другие - худшие?» [8, с. 429]. Попытаемся выявить эпистемологическое поле, в котором, следуя методологии М. Фуко, мы сможем установить «позитивность» нашего знания об этом специфическом и многоликом предмете - искусстве как умении и искусстве как божественном даре. В основе эпистемы, согласно М. Фуко, лежат скрытые структуры, определяющие порядок воплощения вещей в словах; структуры дискурсивных практик различаются в зависимости от уровня организации мышления и культуры исторической эпохи $[9$, c. 32].

Рассмотрим, каким образом интерпретируется искусство в диалоге «Кратил». Спор Сократа и Гермогена выстраивается вокруг остроумно созданной коллизии. Чьим трудом хорошо пользуется ткач, когда работает с челноком? Разумеется, мастера, изготавливающего всевозможные деревянные орудия труда. А всякий ли такой мастер настоящий мастер своего дела? Это тот, кто владеет этим искусством? Конечно же, тот, кто владеет подобным искусством! А чьим трудом хорошо пользуется сверлильщик, когда орудует сверлом? Наверное, кузнеца. А всякий ли человек хороший кузнец или тот, кто знает это искусство? А чьим же трудом пользуется учитель, когда объясняет имена? Тех, кто передал нам имена, которыми мы пользуемся? Их дал закон, установления? В таком случае учитель, когда пользуется именем, пользуется трудом законодателя? А законодателем может быть любой человек или тот, кто знает это искусство? Тот, кто хорошо им владеет. «Таким образом, - подводит итог Сократ, — не каждому человеку дано устанавливать имена, но лишь такому, кого мы назвали бы творцом имен. Он же, видимо, и есть законодатель, а уж этот-то из мастеров реже всего объявляется среди людей» [8, с. 388]. Как видим, искусством следует называть умения не всякого законодателя с учителем и кузнеца с ткачом, но только хороших, лучших в своем деле; их умения взаимосвязаны, ибо они обеспечивают жизнедеятельность полиса, мастерство является мерилом их значимости для сограждан. Среди разнообразных искусств Платон отмечает редкое среди людей искусство философии и художественное творчество.

Платон в «Софисте» особо выделяет искусства производительные (творческие), о которых говорится, что они наиболее небесполезные в сравнении с искусствами подражательными; искусство творчества образов - вершина человеческой деятельности [10, с. 278]. Прежде всего творческие искусства могут быть божественными либо человеческими. Кроме того, оба эти искусства могут создавать либо вещи, либо только образы вещей (образы могут соответствовать реальным соотношениям вещей, либо не соответствовать). Никто из смертных не способен сотворить землю и небо, бескрайнее море, но может создавать те или иные представления. Это искусство сотворения образов Платон, как и Аристотель, называет подражанием [10, с. 340]. Допускается возможность продуктивной неискусной деятельности, многие люди пользуются неискусным навыком даже там, где требуется высокое мастерство, например в красноречии, что объясняется дихотомией искусства и безыскусной природы.

Своеобразны базовые характеристики того, что Платон называет искусством. Во-первых, это множественность и вариативность: однотипность искусств ткацкого, сапожного, плотницкого и корабельного не вызывает сомнений, но в этом же ряду перечисляются искусства поварское, врачебное и повивальное, игры на флейте и метания копья, 
искусство земледелия и измерительное, искусства судебное и составления речей, жреческое и искусство гадания, законодательное и царское - искусство государственного управления людьми, гимнастики и верховой езды, диалектики и спора, искусство (умение) ухода за скотом и искусство (без сомнения, искусство) врачевания души. Во-вторых, это жизненная польза и эмотивная ценность: следует выбирать среди знаний то, что принесет нам пользу; к примеру, от умения обнаруживать залежи золота мы «ничего бы не выгадали» [7, с. 134], золото обладает только символической ценностью. Поэтому необходимо такое знание, в котором сочетается «уменье что-то делать и уменье пользоваться сделанным» [7, с. 135].

Эстетика Платона представляет собой, в изложении А. Ф. Лосева, логически сконструированную модель: «Идеальная модель вещи, порождает эту вещь не только субстанциально, но и логически. А это соединение субстанциального и логического понимания как раз и обеспечивает собою то, что раньше мы называли просто мифом. Миф есть субстанциальное (не просто аллегорическое или метафорическое) осуществление логического понятия» [11, с. 171]. К искусствам Платон относит в том числе производственные, основанные на привычке и бессознательной практике приемы, а также приемы более творческого характера, «когда налицо есть уже некоторое их осознание, хотя это последнее само по себе вовсе недостаточно для какого-нибудь положительного отношения к искусству» [6, с. 23]. Таким образом, вся наличная действительность состоит из бесконечного ряда различных искусств (подразумевается фактически тождественность художественного акта, научного построения, ремесленного изделия).

Аристотель в «Никомаховой этике» уподобляет искусство учению и определяет его сущность практическим выбором: «Всякое искусство и всякое учение, а равным образом поступок и сознательный выбор, как принято считать, стремятся к определенному благу» [12, с. 54]. Определенные цели искусства (как и определенные отдельные от них результаты), позволяют уподобить многие искусства многим наукам: «У врачевания - это здоровье, у судостроения судно, у военачалия - победа, у хозяйствования - богатство» [12, с. 54]. Система искусств у Аристотеля структурирована: науки и умения соподчинены, «подобно тому, как искусство делать уздечки и все прочее, что относится к конской сбруе, подчинено искусству править лошадьми» [12, с. 85]. Показателен моралистический контекст, выявляющий ценностный аспект человеческой деятельности, в котором искусства оказываются столь же функциональны, как и экономические познания и хозяйственные навыки. «Если же у того, что мы делаем, существует некая цель, желанная нам сама по себе, причем остальные цели желанны ради нее и не все цели мы избираем ради иной цели, то ясно, что цель эта есть собственно благо, то есть наивысшее благо» [12, с. 55]. Очевидно само целеполагание: «Даже если для одного человека благом является то же самое, что для государства, более важным и более полным представляется все-таки благо государства, достижение его и сохранение» [12, с. 55]. Законы искусства и принципы творчества должны подчиняться этому закону. Ничто божественное не предопределяет его возвышенную цель? А как же гомеровский дар богов?

Любопытно, что Аристотель, объясняя аксиологическую природу искусств в сопоставлении с добродетелями (где «имеем дело с удовольствиями и страданиями»), утверждает то же самое об эмотивной стороне знаний и умений: «Совершенство искусства - в самих его творениях, ибо довольно того, что они обладали известными качествами» [12, с. 83]. Особую значимость обретает деонтология искусства как «склада души, причастного к истинному суждению и предполагающего творчество» [12, с. 176]. Душевный склад является необходимостью и для искусства, и для рассудительности, «однако если для искусства существует добродетель, то для рассудительности - нет» [12, с. 177]. Затрагивается и вопрос об эмотивной стороне человеческих знаний и умений: только к искусству приложимо это требование - вызывать эмоции, психические реакции реципиента. В самом деле, удовольствие или страдание не может вызвать теорема о равенстве суммы прямых углов треугольника! Мудрость в искусствах никак не сродни рассудительности, поскольку речь идет о совершенстве произведений искусства. Эстетическая значимость (ценность как определенное соотношение значений) произведения искусства никак не сродни удовольствию («удовольствий ищут дети и звери»). Искусство, как заявлял Ф. Шиллер в «Письмах об эстетическом воспитании человека», есть нечто большее, чем «царство эстетической видимости»; «потребность в нем существует в каждой тонко настроенной душе» [13, с. 357]. Специфические продукты активной духовной деятельности являются сложными и противоречивыми переводами материального на язык идеального. Следует различать удовольствия (они разного свойства и смысла) и то, что их доставляет. «Не существует никакого искусства удовольствия, в то время как всякое благо дело искусства» [12, с. 212].

Таким образом, все искусства для Аристотеля есть «науки творческие»; специфика искусства - «прекрасного вообще» - заключается в «собственной, вполне ему имманентной, целесообразности» художественного предмета (художественный объект случаен, в нем нет никакой жизненно-утилитарной целесообразности). Практическая же деятельность человека имеет значение только как целесообразная; практичность есть «разумно приобретенное свойство души, осуществляющее людское благо». Однако красота в искусстве и мораль - разные приобретения человеческой души. Художественное творчество, эстетическое переживание не могут противоречить морали: «...искусство и мораль только поддерживают друг друга» [14, с. $434-435]$.

Согласно сложившемуся мнению, характерному не только для отечественного, но и для зарубежного научного дискурса - «материалист» Аристотель (его эстетика, имеющая риторические задачи, согласно А. Ф. Лосеву, онтологическая) как бы поправлял «идеалиста» Платона (его эстетика, имеющая воспитательные задачи, согласно А. Ф. Лосеву, объективно-идеалистическая) [15]. Весьма показательно известное заявление Аристотеля: «Идеи ввели близкие нам люди, однако долг наш - ради спасения 
истины отказаться даже от дорогого и близкого, особенно если мы философы» [12, с. 59]. В трактовке искусства они разошлись достаточно далеко: если для Платона эстетический принцип не только утилитарен, но одновременно и трансцендентен, то для Аристотеля эстетический принцип формирует дескриптивную модель изучения прекрасного; к тому же его эстетика выражения политически заострена. Художественная реальность у Аристотеля носит вероятностный характер; Платона интересует не художественно преображенная действительность, а сам эстетический предмет, перспективы его познания и жизненные (творческие) модификации его сознания. Идеальное Платон решительно отделяет от материального и признает автономное существование особого мира идей, где безраздельно правит один божественный закон - «благо само по себе». Идеальное для Аристотеля - за исключением области чистого мышления и незримого царства самого божества - не существует и не может существовать помимо материального [15].

Расхождения во взглядах на суть исследуемой проблемы потребления искусства, имеющие место в трудах Аристотеля, продолжающих определенную проблематику сочинений Платона, объясняются не только чисто философскими аспектами. Вопреки хрестоматийным оценкам их наследия и деятельности в заданной советскими исследователями марксистской парадигме, религиозно-этический момент существенен для оценки взглядов обоих - и «как бы идеалиста» Платона, и «как бы материалиста» Аристотеля [15]. Вчитаемся внимательно в один любопытный отрывок из «Метафизики» Аристотеля: «Что же касается сущности и природы единого, то необходимо выяснить, как обстоит здесь дело, подобно тому, как мы при рассмотрении затруднений разбирали, что такое единое и как его надо понимать, а именно: само по себе единое есть некоторая сущность (как это утверждали сначала пифагорейцы, а затем Платон) или скорее в его основе лежит некоторое естество» [16, с. 255-256]. Может ли материалист утверждать, как это делает Аристотель, что само сущее не может быть сущностью (в смысле единого помимо множества, ибо оно общее всему)? Возникает логично еще один вопрос, но уже обратного свойства: может ли идеалист предполагать в едином (о котором говорится в стольких же смыслах, что и о сущем) «нечто определенное по качеству»? [16, с. 256]. Природа рассматривается им как единство неодушевленного и одушевленного, следовательно, необходимое дополнение Единого-сущности Единым-естеством вряд ли может означать что-либо иное, нежели Божество! Сходные суждения Платона выражают тот же философский деизм. Так, Сократ в его изложении в диалоге «Алкивиад II» говорит следующее: «Так не кажется тебе, что требуется очень сильный дар провидения, чтобы как-нибудь невзначай, полагая обрести благо, не вымолить себе величайшего зла, когда боги расположены дать молящему именно то, о чем он просил? Например, об Эдипе рассказывают, будто он просил у богов, чтобы его сыновья медью делили отцовское достояние. Вместо того чтобы молить, как это было еще возможно, об отвращении уже нависшего над ним зла, он накликал еще новое зло» [17, с. 138]. Принципиально человеческий ум признается неспособным постичь природу высшего знания о жизни; ссылка на предание об Эдипе Платоном дана в форме сжатого пересказа соответствующего фрагмента трагедии Еврипида «Финикиянки» [15]. Поэтический вымысел воспринимается не как софистический аргумент, а как фракт истины!

Какова теоретическая основа проблемы потребления искусства вообще? Ключевой вопрос художественной рецепции всякого произведения искусства - об активном восприятии - связан не только с вопросом о природе индивидуального опыта реципиента, рационально-эмоциональным прочтением этого произведения, но и с вопросом об общественной значимости произведения искусства. Онтология любого произведения искусства как результата когнитивного восприятия созданного художником шедевра исторически обусловлена; этот специфический материальный объект взаимодействует с динамичными и одновременно устойчивыми социальными полями - национальными концептами повседневной культуры. Устойчивость задается определенной программой восприятия: к примеру, сюжет античной трагедии должен быть хорошо знаком потенциальному зрителю по мифологическим преданиям, последовательность событий, диалогическое взаимодействие героя с хором предопределено литературной традицией, система пластических образов и взаимосвязанная с ней система идей обусловлены той или иной степенью новаторства драматурга.

Производство и потребление, как утверждал К. Маркс в «Экономических рукописях 1857-1858 гг.», диалектически связаны друг с другом: «Предмет искусства - нечто подобное происходит со всяким другим продуктом — создает публику, понимающую искусство и способную наслаждаться красотой» [18, с. 718]. Сама практика потребления предполагает, что продукт искусства (не как овеществленная деятельность, но как внутренний образ) порождает потребность в новом производстве (интерпретации), т. е. создает «идеальный, внутренне побуждающий мотив» [19, с. 70]. Потребление завершает акт производства, только таким образом заканчивает продукт, лишая его самостоятельновещной формы, реализуя способности потребителя как реципиента.

Художник включен в систему общественных отношений, которыми устанавливаются общепризнанные функции искусства. Успех известных творений великих трагиков, а также антивоенных комедий Аристофрана, так или иначе выражавших парадигму поколения марафонских победителей, связан с социальным заказом. Актуальность тем обусловлена повесткой дня текущей жизни полиса, любимцы публики подотчетны демосу через архонтов, автор зачастую - это драматург и постановщик одновременно, иногда еще и актер. Драматические поэты соперничали на празднествах Дионисий как лучшие граждане, не как современные свободные художники, зависимые от индустрии развлечений, моды и предпочтений публики, однако вполне независимые от общественного мнения, а тем более государства; величина награды за первое место определялась финансовым состоянием полиса [15]. Лавровые венки и звонкое золото в награду прославленным 


\section{ФИЛОСОФИЯ}

поэтам введут в обиход эллинистические монархи и просвещенные тираны.

Весьма характерна одна из сюжетных ситуаций гомеровской «Одиссеи»: «богоравный муж» Одиссей, «городов сокрушитель», по воле судьбы в который раз избежавший гибели в морской пучине, оказывается на острове счастливцев, радушно принят царской семьей. Наутро по повелению царя Алкиноя во дворец по случаю устроенного в честь гостя пиршества приглашается певец Демодок, «дар песней приял от богов он дивный, чтоб все воспевать, что в его пробуждается сердце» [20, с. 83]. Вымышленный «знаменитый певец» наделяется чертами самого легендарного автора: «Муза его при рождении злом и добром одарила: очи затмила его, даровала за то сладкопенье». Муза же побуждает певца «возгласить о вождях знаменитых», выбрав что-нибудь из повествования о храбром Ахилле и мудром Одиссее [15]. Хозяева и гости, наплакавшись, прервав пир ради спортивных развлечений (состязаний в кулачном бою, борьбе утомительной, в беге проворном), заказывают вдохновенному Демодоку другую - «песнь о прекраснокудрявой Киприде и боге Аресе» [20, с. 87]. Растроганный Одиссей просит спеть «теперь о коне деревянном» (о падении Трои). «Можно подумать, что сам был участник всему иль от верных все очевидцев узнал ты», - вот любопытная похвала Одиссея как слушателя Демодоку как исполнителю [15]. В знак благодарности он посылает умелому певцу «полную жира хребтовую часть острозубого вепря взявши с тарелки своей» (почетную часть приготовленного блюда), выказав уважение к певцу: «Его и печальный я чту несказанно» [20, с. 92]. Замечательная картина простоты патриархальных нравов! Гомер к тому времени стал уже школьным классиком!

Итак, оба представителя философской классики - Платон и Аристотель - обосновали и даже возвысили неизменную античную потребность в совмещении производства и красоты: «...греческий художник гордился тем, что его называли ремесленником» [11, с. 794]. Всякое достойное внимания художественное произведение, созданное путем искусства, т. е. соответственно требованиям разума, отвечает не частному, но общему интересу. Причастный к настоящему искусству, лучший и наиболее умелый мастер, разумно разделяя сложное на простое и объединяя простое в сложное, искусно раскрывает суть вещей и образов. Искусство, поступая согласно природе, учит различать добро и зло, тем самым служит общему благу. Обладающий искусством слова хорошо знает, что для публики является общим и что частным, учитывает в своем творчестве общность интересов индивидуума и всего полиса. Таким образом, истинное искусство есть диалектика общего и единичного, порождающая дихотомию творчества и потребления.
1. Фромм Э. Иметь или быть? М. : АСТ, 2018. 320 с.

2. Библер В. С. От наукоучения - к логике культуры: Два философских введения в двадцать первый век. М. : Политиздат, 1990. 413 c.

3. Кобляков А. А. Синергетика, язык, творчество // Синергетическая парадигма. Нелинейное мышление в науке и искусстве / отв. ред. В. А. Копцик. М. : Прогресс-Традиция, 2002. C. 322-332.

4. Аристотель. Поэтика // Соч. : в 4 т. М. : Мысль, 1984. T. 4. С. $645-680$.

5. Пушкин А. С. Поэт и толпа // Собр. соч. : в 10 т. М. : Изд-во АН СССР, 1962-1963. Т. 2. С. 87-89.

6. Лосев А. Ф. История античной эстетики : в 8 т. Т. 3. Высокая классика. М. : АСТ, 2000. 624 с.

7. Платон. Евтидем // Платон. Диалоги. М. : Мысль, 1986. C. 113-157.

8. Платон. Кратил // Собр. соч. : в 4 т. М. : Мысль, 1990. T. 1. C. $383-440$.

9. Фуко М. Слова и вещи. Археология гуманитарных наук. СПб. : A-cad, 1994. 408 c.

10. Платон. Софист // Собр. соч. : в 4 т. М. : Мысль, 1993. T. 2. C. 275-345.

11. Лосев А. Ф. История античной эстетики : в 8 т. Т. 2. Софисты. Сократ. Платон. М. : АСТ, 2000. 846 с.

12. Аристотель. Никомахова этика // Соч. : в 4 т. М. : Мысль, 1984. Т. 4. С. 53-294.

13. Шиллер Ф. Письма об эстетическом воспитании человека // Собр. соч. : в 7 т. М. : Худож. лит., 1957. Т. 6. C. $231-359$.

14. Лосев А. Ф. История античной эстетики : в 8 т. Т. 4. Аристотель и поздняя классика. М. : АСТ, 2000. 880 с.

15. Мисюров Н. Н. Аристотелевский «мимесис» и платоновский «эйдос» как две стороны проблемы потребления искусства в античном обществе // Античный вестник. 1999. Вып. 4-5. С. 32-44.

16. Аристотель. Метафизика // Соч. : в 4 т. М. : Мысль, 1984. Т. 1. С. $63-448$.

17. Платон. Алкивиад // Собр. соч. : в 4 т. М. : Мысль, 1990. T. 1. С. 125-141.

18. Маркс К. Экономические рукописи 1857-1858 гг. // Маркс К., Энгельс Ф. Соч. : в 39 т. М. : Изд-во полит. лит., 1958. T. 12. С. 709-738.

19. Науман М. Введение в основные теоретические и методологические проблемы // Общество. Литература. Чтение. Восприятие литературы в теоретическом аспекте / под ред. О. Г. Егорова. М. : Прогресс, 1978. С. 29-83.

20. Гомер. Одиссея. М. : Наука, 2000. 544 с.

(C) Мисюров Н. Н., 2020 